\section{Resiliencia, Pobreza y Ruralidad}

\section{Resilience, Poverty and Rurality}

\section{Sr. Editor:}

Diversos estudios constatan que la situación social de pobreza socioeconómica es un factor de riesgo psicosocial en general y de salud mental en particular, que afecta de manera especial a los sectores rurales ${ }^{1}$. Más de la mitad de los hogares rurales aun vive en pobreza y cerca de un tercio en situación de pobreza extrema, siendo los hogares más pobres aquellos donde vive mayor cantidad de niños ${ }^{2}$. La problemática más grave que subyace a este punto es que niños y adolescentes rurales que viven en esta condición de exclusión, muchas veces se ven empujados a abandonar la escuela e ingresar prematuramente al mundo del trabajo, perpetuándose de este modo las condiciones de marginación, segregación y pobreza de generación en generación, lo que trae consigo el aumento de riesgo psicosocial ${ }^{3}$. Esto confirma la gravedad del problema de la niñez en pobreza y la necesidad de emprender acciones urgentes.

La literatura ha descrito ampliamente el rol de la educación en la reducción de desigualdades, particularmente en la pobreza y las consecuencias que ésta lleva consigo, entre otros, el aumento de enfermedades de diversa índole desarrolladas cada vez a edad más temprana. Sin embargo, la educación para la población rural ha sido escasamente atendida y América Latina no ha sido una excepción ${ }^{4}$, pese a que los estudios muestran índices de pobreza sistemáticamente más altos en las zonas campesinas y disparidades importantes entre los países, que hacen de éste un desafío de relevancia.

Cabe señalar que la relación entre educación, ruralidad y pobreza, no es simple y ha ido variando según las modificaciones registradas en estos componentes. La experiencia acumulada en materia de educación para la población rural y las transformaciones del espacio rural ponen en un nuevo contexto esa relación y, a la vez, demandan una mirada que atienda las necesidades de los niños y jóvenes desde su propio entorno, incorporando experiencias situadas que consideren las particularidades que coexisten en el entorno rural ${ }^{5}$.

Frente a este escenario parece relevante preguntarse cuáles son las alternativas, sobre todo recordando que la educación es un área estratégica para la promoción de la salud y la prevención de consecuencias derivadas de la pobreza. En el caso rural, destaca su papel privilegiado en la tarea de interrumpir la transmisión de este fenómeno de padres a hijos y en mejorar las oportunidades de bienestar futuro, toda vez que por medio de su escuela, la acción educativa alcanza a las zonas geográficas más alejadas y de menor grado de desarrollo, transformándose en un recurso y beneficio para sus habitantes, especialmente niños y jóvenes.

Dado lo anterior, una alternativa plausible es la que presenta la resiliencia (conjunto de procesos sociales e intra psíquicos que posibilitan tener una vida sana, viviendo en un medio insano), dado su reconocido aporte a la educación en contextos vulnerables ${ }^{6}$. Es sabido que esta condición, al promoverse desde el contexto educativo, atenúa condiciones de vida desafiantes, favorece el aprendizaje y disminuye las probabilidades de deserción escolar, incidiendo sobre situaciones de marginalidad, pobreza y exclusión, y de sus consecuencias.

Lamentablemente, pese al reconocido valor de la resiliencia en la educación, existe escasa investigación respecto de lo que sucede en el ámbito rural. Trabajar en este aspecto podría no sólo contribuir a mejorar los bajos resultados de aprendizaje en este contexto, sino además a promover el desarrollo de competencias que hagan frente a situaciones de vulnerabilidad. De este modo, la escuela rural constituye un espacio fundamental para que las actuales y futuras generaciones campesinas desarrollen conocimientos, habilidades y destrezas necesarias para promover y cuidar de su salud, la de su familia y su comunidad, así como crear y mantener ambientes de estudio, trabajo y convivencias saludables, rompiendo el circulo de la desigualdad social.

En este sentido, las investigaciones han demostrado la relevancia del profesor como un actor estratégico en la promoción de resiliencia como factor protector en estudiantes vulnerables. De esta forma, un profesor que promueve el desarrollo de esta condición, es aquel que proporciona ambientes óptimos para el desarrollo emocional, intelectual, físico y social de los niños y jóvenes campesinos, lo que convierte a esta temática es un aspecto relevante, dados los altos índices de pobreza de zonas rurales de la Región, la necesidad de mejorar la salud y educación a la acceden los niños y niñas que habitan en estos sectores y 
al rol que cumple el profesor en el campo, el que en muchas ocasiones se convierte en un referente social y gestor comunitario.

La apuesta es promover, fomentar y permitir, por medio de la educación rural, la adquisición de habilidades personales y sociales que conduzcan a desarrollar valores y actitudes positivas hacia la salud. De esta manera, la promoción de la resiliencia al interior de las aulas rurales, permitiría -entre otros- el desarrollo de capacidades en la toma de decisiones, la participación, el autocuidado, la solidaridad, cooperación e igualdad. El papel del maestro rural, por tanto, sobrepasa el aspecto centrado sólo en la enseñanza y aprendizaje de contenidos curriculares; por el contrario, su rol radica en favorecer y permitir el despliegue de las habilidades mencionadas, apuntando hacia el verdadero desarrollo integral del estudiante.

A pesar de que no se cuenta con información en el ámbito de la resiliencia, la educación rural y el rol del profesor en particular como promotor de salud, esta reflexión explora el fenómeno de una manera que representa una de las perspectivas posibles. De este modo, constituye un esfuerzo por visibilizar las necesidades y sensibilidades específicas que requiere el contexto campesino. Es una invitación para fomentar avances hacia una educación y salud de calidad en los entornos rurales que más lo necesitan.

\section{Daniela Vera-Bachmann}

Doctor en Ciencias de la Educación (PhD). Académica Escuela de Psicología, Universidad Austral de Chile, Sede Puerto Montt.

Agradecimientos: Esta reflexión surge a partir del trabajo en terreno del proyecto FONDECYT No 11130302, denominado "Escuelas rurales académicamente exitosas: experiencias susceptibles de replicar para la mejora de la educación rural chilena", financiado por CONICYT y ejecutado entre octubre de 2013 y octubre de 2015.

Conflictos de intereses: ninguno que declarar.

\section{Referencias}

1. CEPAL. Pobreza Infantil en América Latina y el Caribe. En: CEPAL, Panorama Social en América Latina. Santiago, Chile: Editorial Naciones Unidas 2013. p. 93-131.

2. PNUD. Informe sobre Desarrollo Humano 2013. Washington DC., Estados Unidos: Editorial PNUD 2013.

3. RMISP. Pobreza y Desigualdad, Informe Latinoamericano 2013. Santiago, Chile: RIMISP, IDRC-CRDI, FIDA Eds.; 2014.

4. Vera-Bachmann D, López M. Resiliencia Académica: una alternativa a explorar en la educación de niños y niñas en contextos rurales. Integra Educativa 2014; 7 (2): 187-204.

5. Díaz R, Osses S, Muñoz S, Alarcón A. Trabajo integrado "centro de salud-escuela", una vía para mejorar la posibilidad de desarrollo de niños campesinos e indígenas de zonas rurales. Salud Pública de México 2014; 56 (3): 241-2.

6. Acevedo V, Restrepo L. De Profesores, Familias y estudiantes: Fortalecimiento de la Resiliencia en la Escuela. Revista Latinoamericana de Ciencias Sociales, Niñez y Juventud 2012; 10 (1): 301-9.

Correspondencia a:

Daniela Vera-Bachmann

Dirección postal: Universidad Austral de Chile. Los Pinos s/n

Balneario Pelluco, Puerto Montt.

Teléfono: +56-65-2277153

danielavera@spm.uach.cl 